\title{
Analysing the correlation between social network analysis measures and performance of students in social network-based engineering education
}

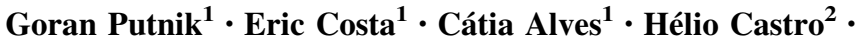 \\ Leonilde Varela $^{1} \cdot$ Vaibhav Shah ${ }^{1}$
}

Accepted: 5 June 2015/Published online: 11 June 2015

(C) Springer Science+Business Media Dordrecht 2015

\begin{abstract}
Social network-based engineering education (SNEE) is designed and implemented as a model of Education 3.0 paradigm. SNEE represents a new learning methodology, which is based on the concept of social networks and represents an extended model of project-led education. The concept of social networks was applied in the real-life experiment, considering two different dimensions: (1) to organize the education process as a social network-based process; and (2) to analyze the students' interactions in the context of evaluation of the students learning performance. The objective of this paper is to present a new model for students evaluation based on their behavior during the course and its validation in comparison with the traditional model of students' evaluation. The validation of the new evaluation model is made through an analysis of the correlation between social network analysis measures (degree centrality, closeness centrality, betweenness centrality, eigenvector centrality, and average tie strength) and the grades obtained by students (grades for quality of work, grades for volume of work, grades for diversity of work, and final grades) in a social network-based engineering education. The main finding is that the obtained correlation results can be used to make the process of the students' performance
\end{abstract}

Eric Costa

eric@dps.uminho.pt

Goran Putnik

putnikgd@dps.uminho.pt

Cátia Alves

catia.alves@dps.uminho.pt

Hélio Castro

heliocastro@parallelplanes.com

Leonilde Varela

leonilde@dps.uminho.pt

Vaibhav Shah

vaibhav.shah@dps.uminho.pt

1 Department of Production and Systems, University of Minho, 4800-058 Guimarães, Portugal

2 ParallelPlanes, Lda., 4715-288 Braga, Portugal 
evaluation based on students interactions (behavior) analysis, to make the evaluation partially automatic, increasing the objectivity and productivity of teachers and allowing a more scalable process of evaluation. The results also contribute to the behavioural theory of learning performance evaluation. More specific findings related to the correlation analysis are: (1) the more different interactions a student had (degree centrality) and the more frequently the student was between the interaction paths of other students (betweenness centrality), the better was the quality of the work; (2) all five social network measures had a positive and strong correlation with the grade for volume of work and with the final grades; and (3) a student with high average tie strength had a higher grade for diversity of work than those with low ties.

Keywords Social network-based engineering education - Education 3.0 - Project-led education - Social networks - Social network analysis - Students' grades · Correlation

\section{Introduction}

In the last years different education paradigms were codified by some authors as Education 1.0, Education 2.0 and Education 3.0 paradigms (Lengel 2013). While the paradigms Education 1.0 and 2.0 could be considered as the traditional ones (although Education 2.0 models are nowadays under implementation as advanced models, the facts that these are already widely implemented and the emergence of Education 3.0 paradigm makes Education 2.0 paradigm the "traditional" one, especially when compared with Education 3.0 paradigm), the emergent Education 3.0 paradigm puts new challenges to design of new education methodologies. These challenges emanates from the nature of Education 3.0 paradigm.

This paper presents research results related to design and implementation of Social Network-based Engineering Education (SNEE), which is seen as a model of Education 3.0 paradigm. The motivation for developing SNEE is in fact that SNEE is capable to embed the most, if not all, of the Education 3.0 paradigm features.

Education 3.0 is characterized in (Keats and Schmidt 2007) "by rich, cross-institutional, cross-cultural educational opportunities within which the learners themselves play a key role as creators of knowledge artifacts that are shared, and where social networking and social benefits outside the immediate scope of activity play a strong role". According to (Keats and Schmidt 2007), three aspects of Education 3.0 are of particular importance:

(1) the freedom of students in making their own choices;

(2) the concept of students as producers of reusable learning content;

(3) institutional arrangements permit the accreditation of learning achieved, not just of courses taught.

The developed and implemented SNEE model (for details on the implementation site see Chapter 4.1, first paragraph) implements the above features (1) and (2), but the third feature is not implement due to the actual institutional arrangement restrictions.

On the other hand, SNEE is a good representative of the real-life model of interactions on market, especially when this market relies on extensive use of internet. Concerning the relevance of Social Network as the model for organizing education process and as model for analysing the education processes (whether this processes being social network 
processes in fact or not), it could be said that nowadays, every business depends on extensive interaction among actors both internally, within the organization, and externally with its environment and, in this sense, these interactions could be seen as a network and moreover as a social network. These networks of interactions among the actors could be modelled as a social network, whether these interactions make a true social network or not, and analysed by the social network analysis tools, i.e. by the Social Network Analysis (SNA). SNA is an important part of the social networks theory and corresponds to the study of relationships of individuals or groups of individuals. This paper focuses on application of social network paradigm for both organization of the education process and for students' interactions analysis.

A social network consists of a set of actors along with a set of ties of a specified type that link those actors (Borgatti and Halgin 2011). Social networks play a critical role in companies in different ways. E.g. Abbasi et al. (2012) refer that social networks are used in organizations in different ways, such as to "determine the way problems are solved", how organizations are run and how markets evolve, and also to define the extent to which individuals succeed in achieving their goals. Other uses of social network paradigm for organizations are referred in literature, e.g. Borgatti and Li (2009) refer the use of social networks for supply chain management and Vrabic et al. (2012) mention that social networks can be used for discovering autonomous structures within existing manufacturing systems. Social networks have emerged as a key strategy as well, since they facilitate the accelerated flows of information, resources and trust (Dewick and Miozzo 2004).

Concerning the education, it is essential to consider the term "social network" to enhance the understanding of this fact, in both dimensions: (1) to organize the education process as a social network-based process and (2) for students' interactions analysis. In the last years, social networks have been widely used in education and SNA has been applied to understand how students engage with each other and to evaluate the existent communication patterns. The emergence of social networks has created conditions for the development of new paradigms and methodologies in education. In educational institutions, social networks and SNA may be used for activities of peer assessment, discussions and collaborative work. In parallel, learning through projects has also become increasingly important for the learning process of engineering students. Project-led education (PLE) appears as a learning approach where students work together in teams to solve large-scale open-ended projects (Powell and Weenk 2003).

In this paper it was explored the concept of "Social network-based engineering education" (SNEE), designed and implemented as a model of Education 3.0 paradigm, representing a new learning methodology, which is based on the concept of social networks and which represents an extended model of project-led education. This methodology is based on an integration of (1) the social network concept, applied for both organization of the education process and for students' interactions and performance analysis, and (2) PLE. The methodology was developed within an engineering course at University of Minho (see Chapter 4.1, first paragraph).

The objective of this paper is to present a new model for students evaluation based on their behavior during the course and its validation in comparison with the traditional model of students' evaluation. The validation of the new evaluation model is made through an analysis of the correlation between social network analysis measures (degree centrality, closeness centrality, betweenness centrality, eigenvector centrality, and average tie strength) and the grades obtained by students (grades for quality of work, grades for volume of work, grades for diversity of work, and final grades) in a social network-based 
engineering education. In particular, it was intended to find whether the position of a student within the social network positively correlates with its performance in the project.

Many authors have been using SNA measures to make correlation and regression analysis, which reinforces the validity of this study. Some examples can be found in: (1) (Abbasi et al. 2011) where correlation and regression analysis are performed, using SNA measures, to identify the effects of co-authorship networks on the performance of scholars; (2) (Giger et al. 2012) where the authors use object-oriented metrics (OOM) and SNA measures to study the correlation between those metrics/measures and fine-grained source code changes; and (3) (Cimenler et al. 2014) where a regression analysis is performed to study the predictive power of researchers' SNA measures on their citation performance.

Nevertheless, the study presented in this paper contributes for the research area of engineering education, focusing on the development of a new learning methodology in this research area and on the design of new methods for the students' evaluation process.

The main research questions for this study [where some of them were first mentioned as future work by Putnik et al. (2013)] are the following:

Q1: Are SNA measures significantly correlated with the students' final grades?

Q2: Are SNA measures significantly correlated with the students' quality of work?

Q3: Are SNA measures significantly correlated with the students' volume of work?

Q4: Are SNA measures significantly correlated with the students' diversity of work?

These four questions were considered for this study since it is intended to analyse not only the correlation between the SNA measures and the final grades of students but also between the SNA measures and the quality, volume and diversity of their work throughout the project. By the correlation analysis results, the objective is to understand whether the SNA measures can be used for the students' evaluation in each component (quality, volume and diversity) or in global. The questions were found pertinent for the study since the correlation results can contribute to a behavioural theory of learning performance and can also be used for the process of automation of students' performance evaluation, which can contribute to the capacity of education courses scalability.

This paper is structured in six sections. After this introductory section, that presented the main objectives of the paper and the main research questions for the study, "Literature review" section presents a literature review of the relevant concepts for this paper: social networks, social networks analysis, SNA in education, and PLE. In "Framework of social network-based engineering education methodology" section it is shortly presented the concept of SNEE. In "Application of the social network-based engineering education methodology" section an application of SNEE is presented, as well as the experimental procedure and methodologies used in the study. "Analysis and results" section presents the analysis and results of the study. In "Conclusion and future work" section the main findings and limitations are presented, as well as some directions for future work.

\section{Literature review}

\section{Social networks and social network analysis measures}

Research on social networks has grown significantly over the last few years. A social network consists of a finite set of actors and the ties between them (Wasserman 1994). Usually social networks are large networks with self-organization, not bound to a 
predefined size (Obreiter and Gräf 2002). Research on the theory of social networks consists of characterizing network structures (e.g. small-worldness) and actors' positions (e.g. centrality) and relating them with group and actors' outcomes (Borgatti and Halgin 2011). The social network theory considers three basic elements [see e.g. (Barabási 2002; Hawe et al. 2004)]: (1) Actors-network members that can be distinct individuals or collective units; (2) Ties-link actors within a network; and (3) Graphs - visual representations of networks, displaying the actors as nodes and the ties as lines.

As Wellman and Berkowitz (1988) describe the concept of SNA as the study of social structure, Wasserman (1994) considers SNA as a group of quantitative methods for analysing the ties among social entities and their implications. An important aspect in SNA is to identify key players in a network (Borgatti 2006).

There are two levels of relational analysis (Fidalgo 2012): (1) egocentric social network analysis (SNA of a single participant); and (2) overall social network analysis (SNA of the social structure focusing all participants). According to Freeman (2004), SNA is a type of research based on four key assumptions:

1. Is motivated by "structural intuition" which is based on the ties linking social actors;

2. Is based on systematic empirical data;

3. Is based on the use of mathematics and/or computational models;

4. Relies largely on graphics.

SNA allows calculating measures and drawing graphs that describe and illustrate the individual and collective structure of a network (Fidalgo 2012). The main measures calculated in SNA are centrality measures. Centrality measures identify the most prominent actors, i.e. those extensively involved in relationships with other network members (Freeman 1979). The most commonly used centrality measures are: (1) degree centrality; (2) betweenness centrality; (3) closeness centrality; and (4) eigenvector centrality. Degree centrality corresponds to the number of actors with whom a particular actor is directly related (Borgatti 1995). Betweenness centrality represents the number of times an actor connects pairs of other actors (Bonacich 2007). With closeness centrality, it is possible to know how closely actors are connected to the entire social network (Opsahl et al. 2010). Eigenvector centrality calculates a type of relative importance, i.e., important nodes must be neighbours of other important nodes (Ai et al. 2013).

Another important measure that can be considered in SNA is the tie strength (weight of the tie) between actors of a social network (Abbasi et al. 2011). For this measure two theories were established: (1) the theory of "strength of weak ties" introduced by Granovetter (1973); and (2) the theory of "strength of strong ties" developed by Krackhardt (1992). Both theories are valid and can be formed depending on the behaviour of the social network actors. For the first theory, the author states that individual actors obtain new information from weak ties rather than from strong ties since this new information will serve as bridges to different clusters of people. On the other hand, in the second theory, the author suggests that strong ties are important in the generation of trust and lead to the receipt of useful knowledge for improving performance. Levin and Cross (2004) suggest that weak ties provide access to non-redundant information but facilitate faster project completion times, if the project is simple. Contrarily, Hansen (1999) considers that strong ties foster complex knowledge transfer, if knowledge is highly complex. 


\section{Social networks and social network analysis in education}

In the last years, social networks have been widely used in education and SNA has been applied to understand how students engage with each other and to evaluate the existent communication patterns (Palonen and Hakkarainen 2000; Liccardi et al. 2007; VercelloneSmith et al. 2012). The emergence of social networks has created conditions for the development of new paradigms and methodologies in education. In educational institutions, social networks and SNA may be used for activities of peer assessment, discussions and collaborative work.

Given the rise of the use of social networks, multiple new learning methods have been developed. According to Bales (1950), the social dimension of learning has always been of great significance to both teachers and learners. Hong et al. (2012) state that instead of overloading students with solutions, educators should guide them to find the solutions through social learning.

Social networks can improve interaction among peers and between educators and students (Wu 2014). Research in the context of education have shown that social networks have a strong impact on trust (Rienties and Kinchin 2014), problem-based learning and collaborative work (Liccardi et al. 2007), teacher involvement (Daly et al. 2010), and engagement in discussions (Vercellone-Smith et al. 2012). So, understanding how students engage with each other in social network-based learning has become increasingly important. Social network analysis showed to be appropriate for the efficient study of those students' interactions (Martinez et al. 2003; Russo and Koesten 2005).

SNA offers an opportunity to understand how communication among members in a social network-based learning environment influences specific outcomes for group members (Russo and Koesten 2005). According to Vercellone-Smith et al. (2012), SNA reveals the most influential students, as well as those students who are isolated or those who assume roles as mediators within the social network. With this information the social network members can reflect on their collective performance and make decisions on how to move forward to improve that performance (Laat et al. 2007). The SNA measures and the social network graph are of great value to detect the different collaborative or interactions patterns that emerge from the social network-based activities (Martinez et al. 2003). They may also help to clarify the overall level of engagement in the social network, the existing kinds of ties, as well as the speed at which information diffuses among the actors (Vercellone-Smith et al. 2012).

SNA has been applied in education to analyse several types of learning methodologies and activities: computer supported collaborative learning (Martinez et al. 2003); online graduate classes (Russo and Koesten 2005); exchange of messages in discussion forums (Laat et al. 2007; Vercellone-Smith et al. 2012); innovation on intensive Teach-the-Teacher training (Jippes et al. 2010); peer assessment (Lomi et al. 2011); transfer of training (Van den Bossche and Segers 2013); health education nursing practice course (Wu 2014); and professional development programmes for teachers (Rienties and Kinchin 2014). Engineering education is considered an emerging field of research (Hassan et al. 2014) and there is a great potential for improvement regarding the development of new learning methodologies in this research area, using the concepts of social networks and SNA.

The reviewed literature demonstrated the pertinence of the SNA in education. However, in the reviewed literature, the concept of SNEE and the correlation analysis, the subjects of this paper, were not found and therefore these two subjects are found pertinent research and development issues. 


\section{Project-led education methodology}

It has already been demonstrated that traditional learning is no longer the best approach in the students' learning process. This type of learning is mostly an end-term process where the major acquired competency would be the competency to pass final exams (Lima et al. 2007). As such, assisting students in establishing appropriate and effective learning attitudes has become an important task (Tseng et al. 2013). Thus, new methodologies of teaching and evaluating have been adopted in order to improve students' performance, focusing on the development of technical and transversal competencies (Fernandes et al. 2014).

Project-led Education is a methodology that differs from traditional approaches by promoting an active learning process. In this methodology the teacher is no longer a lecturer, but is regarded as a facilitator of learning (van Hattum-Janssen and Vasconcelos 2008). PLE is focused on team-based student activity and on solving large-scale openended projects (Powell and Weenk 2003). Students work in groups and plan, develop and deliver a project during an entire semester, based on the integration of contents from different courses of that semester, which allows them to acquire and develop transversal skills (Helle et al. 2006; Fernandes et al. 2007). In PLE, students can also develop several technical skills, such as communication, time management, project management, entrepreneurship, team-work, creativity, critical thinking, or problem solving (Powell and Weenk 2003; Helle et al. 2006; Lima et al. 2007; Fernandes et al. 2007).

The PLE's ideas and approach are often confused with Problem-based Learning (PBL). The main difference between those two learning approaches is essentially related to the scale of learning activities. In PBL there is some emphasis on team-based discussion of smaller-scale problems, which are handled within a week or a few weeks, rather than larger-scale PLE projects over a complete semester (Powell 2004).

However, PLE could be classified as a model belonging to Education 2.0 paradigm.

\section{Framework of social network-based engineering education methodology}

In SNEE students are organized as a social network, in which the work to be assigned is lunched in a crowdsourcing manner. It means that work is launched to all students simultaneously through an auction, and each student can concur to win the work assignment. To provide opportunity, and the condition that each student will do the minimum work required by the learning objectives, (1) the work to be launched should be divided in sufficient number of projects and tasks, and (2) the specific rules for managing tasks distributions and assignments should be defined but to leave the sufficient degree of freedom to the students in choosing which tasks, the number of tasks, the type of tasks they want to realize, and where, when and with whom they want to work. Actually, the students are free to choose which tasks to do at what time at what place at with whom, and to choose freely to interact with teacher or not. Additionally, students have the possibility, and they are stimulated to share the contents they create which in turn became a students generated "reusable learning content" [the students change from the pure consumers (Education 1.0 and 2.0) to prosumers (Education 3.0)].

SNEE methodology is primarily conceived to support active learning, although it could support also the traditional lecture-based methodology. This methodology is seen as a further development of the PLE methodology (since the teaching method is based on the project that integrates two or more subjects) and towards, and as a model of, Education 3.0 (since it embeds Education 3.0 features (1) and (2) referred in Chapter 1). While the 
traditional PLE is based on fixed working groups (formed by students themselves or by teachers), in SNEE, there are predefined groups (which correspond to one type of actors of the social network, i.e. group resources) but there are also other types of actors (project coordinators and individual resources), as well as their self-organization as one of the main emerging features, besides the freedom of choices, of Education 3.0 paradigm.

SNEE, when applied in engineering education, and more specifically in industrial engineering courses, is oriented to teach students the advanced and emerging manufacturing systems and organizations, such as:

- Internet-based work (design, management, operation);

- Product/Service Systems (PSS);

- Cloud and ubiquitous manufacturing systems and enterprises;

- Virtuality;

- Agility;

- Networked organization/Networking (supply-chain);

- Social network-based and community-based manufacturing/production;

- Crowdsourcing;

- Open System architecture-based organization;

- Learning organization;

- Entrepreneurship;

- Advanced ICT;

- Complexity Management in organization;

- Integration and interoperability in organizations;

- Cyber-physical system;

- Negotiation;

- Human-centred view of organization vs Technology-centred;

- Game theory;

- Competition-based environments (markets) and organizations (concurrent engineering);

- Collaboration-based environments (communities) and organizations (collaborative engineering);

- Large-scale open-ended projects;

- Open-source projects;

- $\quad$...

In its extreme, when all institutional arrangements boundaries are removed (which is not the case in the experiment undertaken), in SNEE, students independently study new conceptual material before it is exposed in the classroom. Even teachers' lectures, instructions and explanations could be seen as services that are launched only upon students' requests because they needed to solve the tasks (problems). In that way, the whole process, the teaching and the learning, is subjected to self-organization, and in its implementation is servicizing whose services are used and explored in a dynamic and agile way (in other words, dynamic and agile teaching and learning).

SNEE is conceived under the assumption that students can learn the course's content faster and in a more agile way than in the traditional lecture-based methodology, promoting the development of several important technical and soft skills, such as work agility, self-organization and problem-solving.

The idea of creating this new type of learning methodology was designed to stimulate also a new way of working, in order to prepare the students for a different professional contexts. With the unpredictable employment situation, it is important to instruct students to deal with different approaches (i.e. working in social network-based projects or working 
as freelancers), which differ from the approaches that they are accustomed to (i.e. working in group projects or working with traditional companies).

\section{Application of the social network-based engineering education methodology}

\section{Description}

The application described in this paper corresponds to an academic project that followed the SNEE methodology. The project represented a pioneer experience and was performed during one semester with students from an engineering course. The project was implemented and was part of the evaluation of the subjects of Computer Aided Design/Computer Aided Process Planning (CAD/CAPP) and Computer Aided Manufacturing (CAM) of the 4th year of the Industrial Engineering and Management Integrated Master Course at the University of Minho in Portugal.

Design and implementation of SNEE methodology was motivated by intention to improve, and to make advancements in relation to the previously implemented classical PLE methodology, which had run for several years for the same subjects, and to experiment with the features of Education 3.0 paradigm.

A total of 43 students participated in the project and 6 projects were defined. 6 students were selected as project coordinators. These 6 students, the project coordinators, were playing the roles of "clients" that want to develop their projects and for which they need "resources" (services, service providers, etc.) to execute different project tasks. Each one of the 37 remaining students were assigned as an individual "resource" (individual service provider, i.e. freelancer or individual enterprise) and these 37 students were also organized in 6 working groups representing group, or collective, resource (collective service providers, i.e. enterprise type providers). The last type of "resources" corresponds to the traditional PLE methodology, which is based on working groups. So, the total number of participants was 43 students but in total, the "social network" to realize the assigned projects consisted of 49 actors, i.e. 6 project coordinators (C01, C02, etc.), 37 individual resources (R01, R02, etc.) and 6 group resources (G01, G02, etc.).

Every coordinator was responsible for creating one final document as the project report for evaluation. The report was built using Google Drive which promoted a collaborative environment since it allowed viewing and editing documents by multiple actors at the same time. Each assigned project to be performed was consisted of 95 tasks, making the total of 570 tasks launched to the population of 37 students. The tasks were of two general types of tasks: "individual tasks" and "group tasks". "Individual tasks" were considered the tasks to be executed by the "individual resources" (individual students) only, in order to evaluate individual performance, while the "group tasks" were considered the tasks to be executed by the "group resources" (students working group). All tasks were launched by the project coordinators to all actors simultaneously ("individual resources" and "group resources"), using Google+. After that, each task was assigned based on the negotiation between the coordinator and the candidate resource. Project coordinators used the Gantter application for Google Drive to control the assignments, i.e. to register, monitor and manage precedencies, deadlines and costs of each task. The costs considered in this project were fictitious and were left to the discretion of each actor. Table 1 presents the tools used by the project coordinators and by the resources of the project. 
Table 1 Tools used in the project

\begin{tabular}{|c|c|}
\hline Tools & Functions \\
\hline Google+ & $\begin{array}{l}\text { Creation of profiles for each actor (anonymous profiles) } \\
\text { Communication system between actors } \\
\text { Publication of project tasks }\end{array}$ \\
\hline Gmail and Gmail chat & $\begin{array}{l}\text { Identification of each actor } \\
\text { Communication between actors and between students and professors }\end{array}$ \\
\hline Google Drive & $\begin{array}{l}\text { Creation of project tasks documentation } \\
\text { Storage of project tasks documentation } \\
\text { Collaborative development of project tasks }\end{array}$ \\
\hline Gantter application for Google Drive & $\begin{array}{l}\text { Project management system } \\
\text { Assignment of tasks to the resources } \\
\text { Monitoring and management of tasks execution }\end{array}$ \\
\hline
\end{tabular}

All participants were intensively using all tools referred above, as well as other tools such as Facebook and Dropbox for private communication and to share information. Google + was used since it is becoming a learning platform, allowing "virtual community" to share knowledge and exchange feedback (Wu 2014). This tool integrates several software applications, facilitating simple operation and rapid sharing of information by using various devices (Fitzpatrick and Lueck 2010).

For this project, some important rules and objectives were defined:

- Interactions can only occur between project coordinators and resources ("individual resources" and "group resources"), i.e. coordinators cannot communicate between them and the same happens for the resources, in order to simulate independent clients and service providers in competition on the market (another concept would be where the actors can communicate and share extensively relevant information and knowledge, but this approach would refer to collaborative "market", which was not the research subject in this paper);

- All participants must be anonymous during the entire project, in order to empower teamwork skills with virtually unknown and different people, in order to simulate needs for cooperation with unknown people frequently present in real life situations on the market, to simulate virtuality present in social networks and in concept of virtual enterprises, and to prevent the creation of groups with members who are already used to working together or influence of power and dominance relationships within the group;

- All resources had to get to the end of the project with at least one task performed, preventing that certain resources might be left without any work. Although this rule is not a "rule of the market", it was necessary to introduce it for education reasons;

- The objective of project coordinators at the end of the project was to spend the least amount of "money" possible for accomplishment of the project, while the objective of resources is to earn the most amount of "money" possible. This rule simulates the common objectives on the real market, in which the clients want to minimize the production costs and the service providers want to maximize their earnings. This rule represents the instrument for the process gamification. 


\section{Experimental procedure and methodologies}

The objective of this paper is to present a new model for students evaluation based on their behavior during the course and its validation in comparison with the traditional model of students' evaluation, through an analysis of the correlation between social network analysis measures and the grades obtained by students (grades).

The experimental procedure used consisted of four main steps: (1) monitor and register interactions (ties) between students (actors); (2) evaluate students' work and assign grades; (3) apply social network analysis; (4) analyse the correlation between SNA measures and students' grades.

\section{Methodology for monitoring and registration of interactions}

Since the ties among the actors of this social network could be of different types (such as communication processes, accomplished tasks or failed tasks), in this paper was considered the type of accomplished tasks only. So, for each accomplished task it is established a tie between the project coordinator that launched that task and the resource that accomplished it.

Throughout the project, the project coordinators were monitoring and registering which resources were responsible to perform their tasks. Project coordinators had also the responsibility to review each task (for this activity they were helped and conducted by teachers to assure quality reviewing) and to merge the realised parts and create the final project document. At the end of the projects and with this information, the data regarding all ties that occurred between the social network actors was summarized in a table (excel file), placing the 6 project coordinators in the columns, the 37 individual resources and 6 group resources in the rows, and the number of ties (accomplished tasks) in each table cell for the corresponding pair project coordinator-resource. This table allowed having a global vision of not only the interactions that occurred but also of the quantity of the tasks that a resource performed for each project coordinator.

\section{Methodology for evaluation of students}

Three components were considered for the students' evaluation process: (1) quality of work; (2) volume of work; and (3) diversity of work. Weights were assigned according to the order and given importance of each evaluation component. Equation 1 presents the formula to get the final grade of a student considering each evaluation component:

$$
F G=(0.6 * G Q)+(0.1 * Q V)+(0.3 * G D)
$$

where: $F G$ is the final grade; $G Q$ is the grade for quality of work; $Q V$ is the grade for volume of work; $G D$ is the grade for diversity of work.

Each component was evaluated using a scale ranging from 0 to 20 (by the Portuguese evaluation scale). The tasks of each project were first evaluated according to the quality of the work performed and the grade assigned to each student in this component was the value of the mean of the performed tasks. The evaluation component of volume of work was considered as the quantity of tasks performed by a student, i.e. the more tasks a student accomplishes, the higher the grade will be in this component. For the evaluation of the diversity of work it was taken into consideration the fact that the student performed tasks of one or various areas of expertise (e.g. text writing, creation of technical drawings, CNC program). 


\section{Methodology for social network analysis}

To perform the SNA it was used the software UCINET (Borgatti et al. 2002). First, the interactions data of Step 1 (monitoring and registration of interactions) were converted into an interactions matrix to be uploaded in the software. Each actor identifier $(\mathrm{Ci}$-Project coordinator $i$; $G i$-Group resource $i$; $R i$-Individual resource $i$ ) was placed in the rows of the matrix and was repeated in the columns to form a square matrix of $49 \times 49$ actors. A square matrix was employed since it represents the only type of matrix which can be used in UCINET to calculate SNA measures (Hanneman and Riddle 2005). Only two values were considered in that matrix:

- 1 -when a resource (individual or group) accomplishes a task for a project coordinator;

- 0 -when a resource (individual or group) does not accomplish a task for a project coordinator.

For example, R01 accomplished tasks only for C05 and C06; so, in the R01 row the value 1 is present for the columns $\mathrm{C} 05$ and $\mathrm{C} 06$ and the value 0 is present for the columns $\mathrm{C} 01, \mathrm{C} 02, \mathrm{C} 03$ and $\mathrm{C} 04$. After preparing the interactions matrix, the same software was used to visualize the network and to calculate the following SNA measures:

- Degree centrality;

- Betweenness centrality;

- Closeness centrality;

- Eigenvector centrality.

For these SNA measures it was considered the normalized value $(n=$ normalized [0-1]). In addition to those measures obtained with UCINET, another important SNA measure was calculated:

- Average tie strength.

For this study, the strength of a tie is weighted by the number of performed tasks between resources and project coordinators. In this way, the average tie strength is obtained dividing the actor's total number of ties (total number of tasks) by its degree centrality (Eq. 2):

$$
A T S=\frac{T T}{D C}
$$

where: ATS is the average tie strength; $T T$ is the actor's total number of ties; $D C$ is the actor's degree centrality.

\section{Methodology for correlation analysis}

Correlation analysis is used to describe the strength and direction of the linear relationship between two variables. The Spearman rank order correlation was used to analyse the correlation of the SNA measures (degree centrality, closeness centrality, betweenness centrality, eigenvector centrality, and average tie strength) with the students' grades obtained in the project (grades for quality of work, grades for volume of work, grades for diversity of work, and final grades). The software SPSS was used to perform this correlation analysis. 
Spearman rank order correlation is a nonparametric (distribution-free) rank statistic proposed by Charles Spearman as a measure of the strength of an association between two variables (Hauke and Kossowski 2011). Spearman correlation was used instead of Pearson correlation because: (1) it does not make any assumptions about the distribution of the data and it measures the strength of a monotonic relation (rather than linear) between two variables (Dowdy et al. 2011); (2) it does not require the variables to be measured on interval scales, it can be used for variables measured at the ordinal level (Hauke and Kossowski 2011).

The Spearman correlation coefficients (rho) can only take on values from -1 to +1 , where the sign indicates whether there is a positive correlation (as one variable increases, the other also increases) or a negative correlation (as one variable increases, the other decreases) (Pallant 2010). The size of the absolute value (ignoring the sign) provides an indication of the strength of the relationship: a correlation of 0 indicates no relationship at all, a correlation of 1.0 indicates a perfect positive correlation, and a value of -1.0 indicates a perfect negative correlation. To interpret the values (between 0 and 1) of the correlation coefficients it was used the following rank (Cohen 1988):

- Weak correlation: rho $=0.10$ to 0.29 ;

- Medium correlation: rho $=0.30$ to 0.49 ;

- Strong correlation: rho $=0.50$ to 1.0 .

\section{Hypotheses for the study}

Social network analysis measures were used to suggest relationships that may be related with students' grades. For this study, the expectation is that a student has high grades if he/ she performs many tasks in the project, connects many pairs of other students, is very close to all other students, is connected to many other students that are themselves well-connected, and has a high average tie strength. Figure 1 outlines the hypotheses that were addressed to study the relationship between SNA measures and students' grades.

Table 2 presents the description of each hypothesis to understand in detail the hypotheses generated for this study.

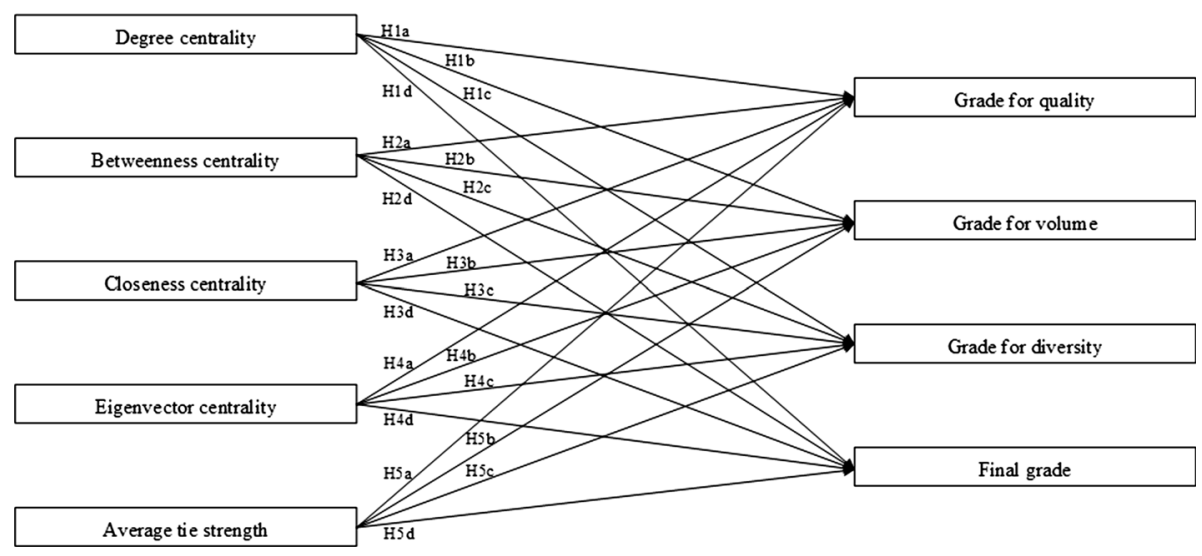

Fig. 1 Hypotheses to study the relationship between SNA measures and students' grades 
Table 2 Description of the hypotheses used for the study

\begin{tabular}{ll}
\hline Hypothesis & Description \\
\hline $\mathrm{H} 1 \mathrm{a}$ & Degree centrality of a student is significantly correlated with the grade for quality \\
$\mathrm{H} 1 \mathrm{~b}$ & Degree centrality of a student is significantly correlated with the grade for volume \\
$\mathrm{H} 1 \mathrm{c}$ & Degree centrality of a student is significantly correlated with the grade for diversity \\
$\mathrm{H} 1 \mathrm{~d}$ & Degree centrality of a student is significantly correlated with the final grade \\
$\mathrm{H} 2 \mathrm{a}$ & Betweenness centrality of a student is significantly correlated with the grade for quality \\
$\mathrm{H} 2 \mathrm{~b}$ & Betweenness centrality of a student is significantly correlated with the grade for volume \\
$\mathrm{H} 2 \mathrm{c}$ & Betweenness centrality of a student is significantly correlated with the grade for diversity \\
$\mathrm{H} 2 \mathrm{~d}$ & Betweenness centrality of a student is significantly correlated with the final grade \\
$\mathrm{H} 3 \mathrm{a}$ & Closeness centrality of a student is significantly correlated with the grade for quality \\
$\mathrm{H} 3 \mathrm{~b}$ & Closeness centrality of a student is significantly correlated with the grade for volume \\
$\mathrm{H} 3 \mathrm{c}$ & Closeness centrality of a student is significantly correlated with the grade for diversity \\
$\mathrm{H} 3 \mathrm{~d}$ & Closeness centrality of a student is significantly correlated with the final grade \\
$\mathrm{H} 4 \mathrm{a}$ & Eigenvector centrality of a student is significantly correlated with the grade for quality \\
$\mathrm{H} 4 \mathrm{~b}$ & Eigenvector centrality of a student is significantly correlated with the grade for volume \\
$\mathrm{H} 4 \mathrm{c}$ & Eigenvector centrality of a student is significantly correlated with the grade for diversity \\
$\mathrm{H} 4 \mathrm{~d}$ & Eigenvector centrality of a student is significantly correlated with the final grade \\
$\mathrm{H} 5 \mathrm{a}$ & Average tie strength of a student is significantly correlated with the grade for quality \\
$\mathrm{H} 5 \mathrm{~b}$ & Average tie strength of a student is significantly correlated with the grade for volume \\
$\mathrm{H} 5 \mathrm{c}$ & Average tie strength of a student is significantly correlated with the grade for diversity \\
$\mathrm{H} 5 \mathrm{~d}$ & Average tie strength of a student is significantly correlated with the final grade \\
\hline
\end{tabular}

\section{Analysis and results}

\section{Experimental procedure results}

The data of the 49 actors involved in this SNEE experience were used for the experimental procedure of the study and for the hypotheses validation. Applying each step of the experimental procedure, it was obtained the data regarding the interactions that occurred during the project, the students' grades, and the SNA measures, allowing performing the correlation analysis.

\section{Monitoring and registration of interactions}

The results for the total number of ties of each social network actor are presented in Table 3. As expected, the value for the project coordinators is 95 (or near 95) ties that occurred throughout the project since it represents the total number of tasks established for each project. As previously mentioned, the type of ties considered for the study is the type of accomplished tasks and there are only two types of ties-the tie between project coordinators and individual resources, and the tie between project coordinators and group resources. In the case of coordinators the value represents the amount of tasks the resources (group and individual) made for their projects, whereas for the resources, the value describes the number of tasks performed for the entire project. $\mathrm{C} 01, \mathrm{C} 02$ and $\mathrm{C} 04$ do not present the value of 95 since some tasks of their projects were not performed by any 


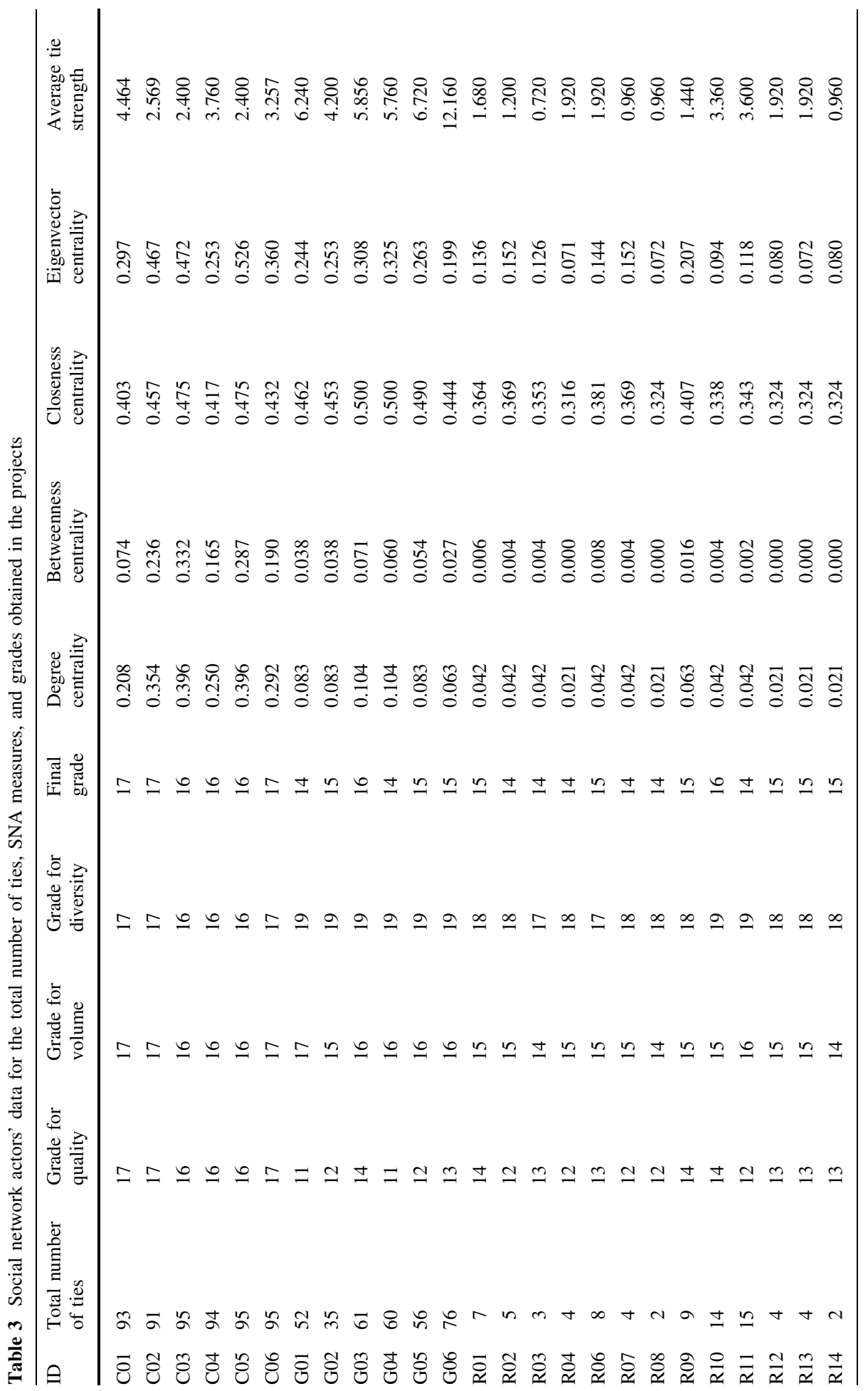




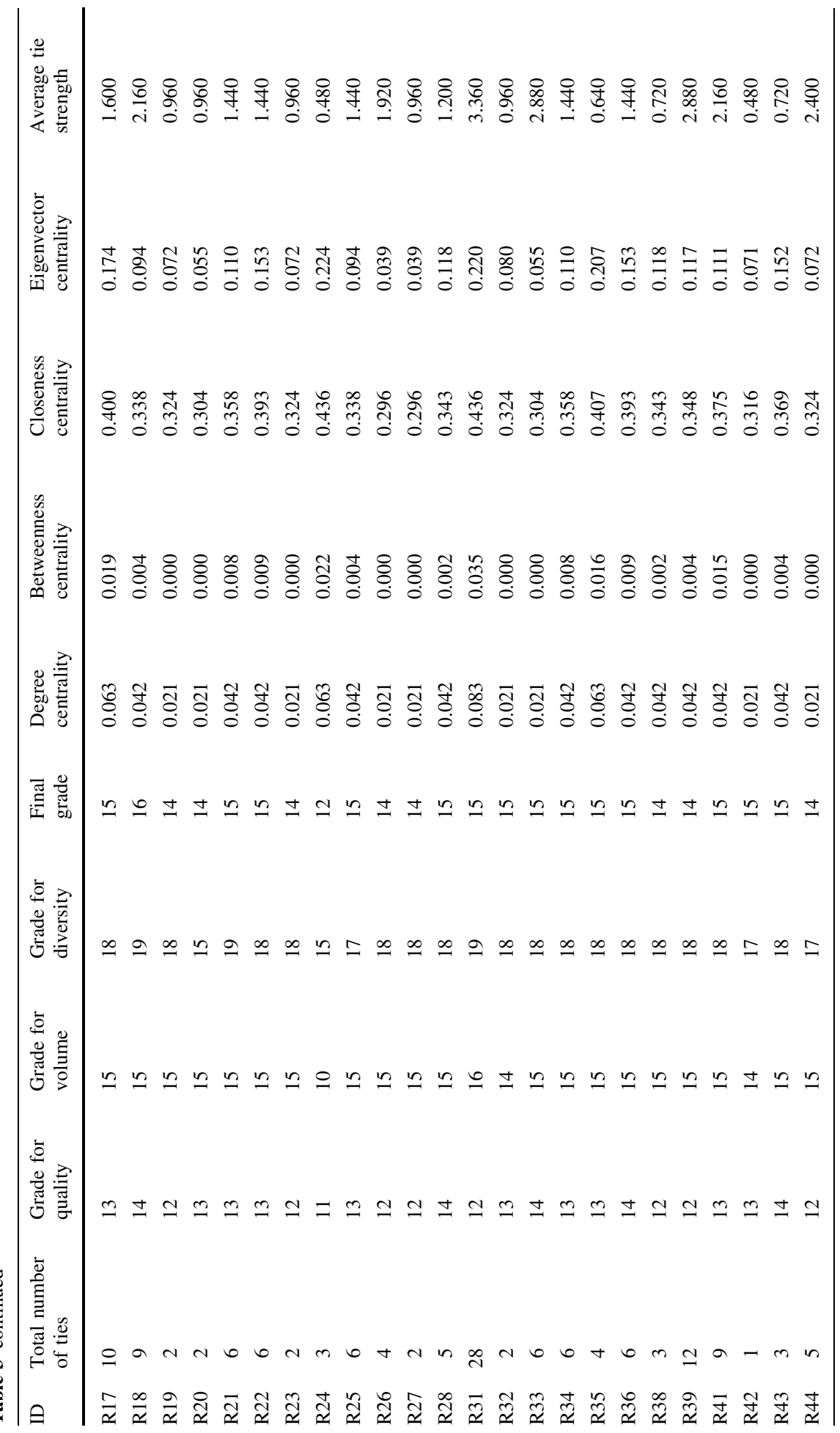


resource or were performed by themselves. As there were more group tasks than individual tasks, the group resources obtained a higher value compared with the individual resources. However, R31 stood out from the rest of the individual resources, presenting a value of 28 performed tasks.

\section{Evaluation of students}

Table 3 presents the grades assigned for each actor (student) of the project, regarding the quality, the volume and the diversity of the work performed. With those three evaluation components it was possible to obtain the final grade of each student.

\section{Social network analysis}

With the interaction data obtained in Step 1 (monitoring and registration of interactions) the interaction square matrix of $49 \times 49$ actors was created and uploaded in UCINET. Figure 2 represents an excerpt from that matrix.

The social network graph of this study (Fig. 3) shows the different connections that occurred between the actors during the project. The different tie strengths are also indicated through the link (line) thickness. The colours red, green, and blue of the nodes are associated to the project coordinators, the group resources, and the individual resources, respectively. With this graph it is possible to visualize the network patterns and to have an idea of how many resources have contributed to each project. For example, R39 has accomplished tasks for C01 and C05, and R32 only made tasks for C05.

The results for the SNA measures of degree centrality, betweenness centrality, closeness centrality, eigenvector centrality, and average tie strength are presented in Table 3 . The analysis of some other aspects of the results obtained for the SNA measures is not within the scope of this paper, as the paper's objective is the correlation analysis.

\section{Spearman rank order correlation}

To test the hypotheses of the study, a Spearman rank order correlation was applied using SPSS. The values obtained for the correlation coefficients, between the students' grades and the SNA measures, are represented in Table 4.

The results show that the each SNA measure impacts differently with the grades obtained by the students. Some correlations are significant (medium or strong correlations) but others present weak or no significant correlation coefficients.

\begin{tabular}{|c|c|c|c|c|c|c|c|c|c|c|c|c|c|c|}
\hline & C01 & $\mathrm{CO} 2$ & $\mathrm{CO}$ & C04 & C05 & $\mathrm{C} 06$ & R01 & R02 & R03 & R04 & R06 & R07 & \begin{tabular}{l|l} 
R08 & . \\
\end{tabular} & Current cell: \\
\hline C01 & 0 & 0 & 0 & 0 & 0 & 0 & 0 & 0 & 1 & 0 & 0 & 0 & 0 & Row. Cot \\
\hline \begin{tabular}{|l|}
$\mathrm{CO} 2$ \\
\end{tabular} & 0 & 0 & 0 & 0 & 0 & 0 & 0 & 1 & 0 & 1 & 1 & 1 & 0 & 0 \\
\hline $\mathrm{CO3}$ & 0 & 0 & 0 & 0 & 0 & 0 & 0 & 0 & 0 & 0 & 1 & 0 & 1 & \\
\hline $\mathrm{CO4}$ & 0 & 0 & 0 & 0 & 0 & 0 & 0 & 0 & 0 & 0 & 0 & 0 & 0 & \\
\hline $\mathrm{CO5}$ & 0 & 0 & 0 & 0 & 0 & 0 & 1 & 1 & 1 & 0 & 0 & 1 & 0 & Dimensions \\
\hline $\mathrm{CO}$ & 0 & 0 & 0 & 0 & 0 & 0 & 1 & 0 & 0 & 0 & 0 & 0 & 0 & Rows: Cols: \\
\hline R01 & 0 & 0 & 0 & 0 & 1 & 1 & 0 & 0 & 0 & 0 & 0 & 0 & 0 & 49 \\
\hline R02 & 0 & 1 & 0 & 0 & 1 & 0 & 0 & 0 & 0 & 0 & 0 & 0 & 0 & \\
\hline $\mathrm{R} 03$ & 1 & 0 & 0 & 0 & 1 & 0 & 0 & 0 & 0 & 0 & 0 & 0 & 0 & \\
\hline R04 & 0 & 1 & 0 & 0 & 0 & 0 & 0 & 0 & 0 & 0 & 0 & 0 & 0 & C Normal \\
\hline R06 & 0 & 1 & 1 & 0 & 0 & 0 & 0 & 0 & 0 & 0 & 0 & 0 & 0 & - Normal \\
\hline R07 & 0 & 1 & 0 & 0 & 1 & 0 & 0 & 0 & 0 & 0 & 0 & 0 & 0 & \\
\hline R08 & 0 & 0 & 1 & 0 & 0 & 0 & 0 & 0 & 0 & 0 & 0 & 0 & 0 & \\
\hline Rog & 0 & 1 & 0 & 0 & 1 & 1 & 0 & 0 & 0 & 0 & 0 & 0 & 0 & \\
\hline R10 & 0 & 0 & 0 & 1 & 0 & 1 & 0 & 0 & 0 & 0 & 0 & 0 & 0 & \\
\hline
\end{tabular}

Fig. 2 Excerpt from the interactions matrix uploaded in UCINET 


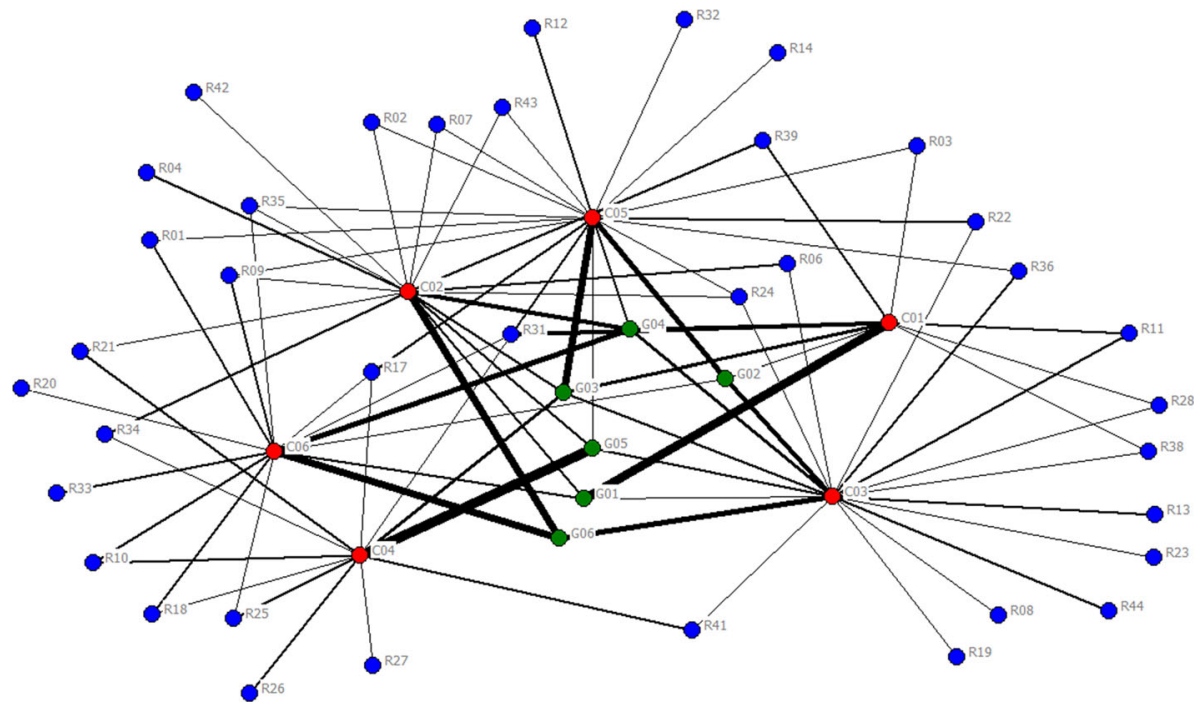

Fig. 3 Social network graph with the representation of project coordinators, group resources and individual resources

Starting with the analysis for the grade for quality, only two of the five SNA measures demonstrate significance, i.e. there was a medium and positive correlation for the degree centrality $(r h o=.32, p<.05)$ and for the betweenness centrality $(r h o=.34, p<.05)$. Those results can be interpreted as: the more different interactions a student had and the more frequently a student was between the interaction paths of other students, the better was the quality of the work.

Based on the results obtained for the grade for volume, it can be stated that there is a strong and positive correlation between the five SNA measures and this evaluation component (all rho above .5, $p<.01$ ). Thus, students who were more central and who had strong ties (i.e. repeated interactions) had better grades in volume of work.

The correlation coefficients between the SNA measures and the grade for diversity of work (not diversity of interactions) showed that only the average tie strength has significance $(r h o=.36, p<.05)$, suggesting that a student who maintained a repeated interaction with another student, rather than keeping single interactions with many different students, had a higher grade for diversity of work.

Finally, analysing the results of the correlation between the five SNA measures and the students' final grades, strong and positive correlation coefficients for all measures are verified. Those values show that students who were more central and who had strong ties had better chances to achieve higher final grades in the projects.

\section{Discussion of hypotheses}

To discuss the validation of the hypotheses the significance level obtained with the correlation analysis and the coefficient of determination for each hypothesis are considered. The coefficients of determination were calculated in order to get an idea of how much variance the two variables in each hypothesis share (Pallant 2010). To do that, the rho 


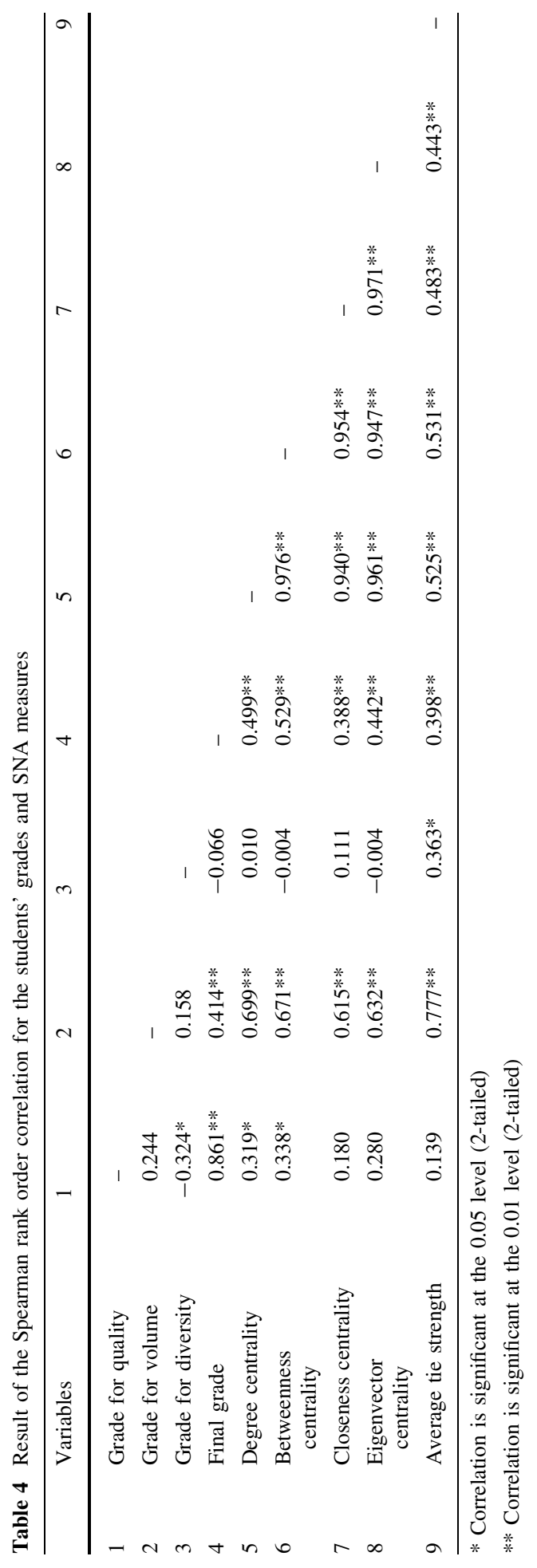


values were squared, e.g. two variables that correlate rho $=.20$ share only $4 \%$ $(0.20 * 0.20)$ of their variance.

Table 5 presents the results obtained for the hypotheses validation.

The results indicate that, from the 20 hypotheses generated for this study, 13 were validated and the other 7 did not present significance in the correlation analysis.

The degree centrality of a student is significantly correlated with the grades for quality, grades for volume and final grades, supporting $\mathrm{H} 1 \mathrm{a}, \mathrm{H} 1 \mathrm{~b}$ and $\mathrm{H} 1 \mathrm{~d}$, respectively. This SNA measure helps to explain $49 \%$ of the variance on the grades obtained by students for the volume of work, which represents the highest coefficient of determination for this measure. However, H1c was not supported, meaning that the degree centrality has no significant correlation with the students' grades for diversity.

For the betweenness centrality the situation is the same as for the degree centrality (H2a, $\mathrm{H} 2 \mathrm{~b}$ and $\mathrm{H} 3 \mathrm{~d}$ were validated and $\mathrm{H} 1 \mathrm{c}$ was not validated). In this case, the value of the highest coefficient of determination represents almost $45 \%$ of shared variance between the students' betweenness centrality and grades for volume.

The SNA measure of closeness centrality has significant correlations with the grade for volume and with the final grade, helping to support $\mathrm{H} 3 \mathrm{~b}$ (coefficient of determination of $38 \%$ ) and $\mathrm{H} 3 \mathrm{~d}$ (coefficient of determination of $15 \%$ ), respectively. The students' grades for quality (H3a) and grades for diversity $(\mathrm{H} 3 \mathrm{c})$ do not present significant correlation with this SNA measure.

Table 5 Hypotheses validation, and indication of the significance and of the coefficient of determination for each hypothesis

\begin{tabular}{llll}
\hline Hypothesis & Validation & Significance & Coefficient of determination (\%) \\
\hline H1a & $\sqrt{ }$ & $(r h o=.32, p<.05)$ & 10.24 \\
H1b & $\sqrt{ }$ & $(r h o=.70, p<.01)$ & 49.00 \\
H1c & $\times$ & - & - \\
H1d & $\sqrt{ }$ & $(r h o=.50, p<.01)$ & 25.00 \\
H2a & $\sqrt{ }$ & $(r h o=.34, p<.05)$ & 11.56 \\
H2b & $\sqrt{ }$ & $(r h o=.67, p<.01)$ & 44.89 \\
H2c & $\times$ & $(r h o=.53, p<.01)$ & - \\
H2d & $\sqrt{ }$ & - & 28.09 \\
H3a & $\times$ & $(r h o=.62, p<.01)$ & - \\
H3b & $\sqrt{ }$ & $(r h o=.39, p<.01)$ & 38.44 \\
H3c & $\times$ & - & - \\
H3d & $\sqrt{ }$ & $(r h o=.63, p<.01)$ & - \\
H4a & $\times$ & - & 39.69 \\
H4b & $\sqrt{ }$ & $(r h o=.44, p<.01)$ & - \\
H4c & $\times$ & - & 19.36 \\
H4d & $\sqrt{ }$ & $(r h o=.78, p<.01)$ & - \\
H5a & $\times$ & $(r h o=.36, p<.05)$ & 60.84 \\
H5b & $\sqrt{ }$ & $(r h o=.40, p<.01)$ & 12.96 \\
H5c & $\sqrt{ }$ & & 16.00 \\
H5d & $\sqrt{ }$ & & \\
\hline
\end{tabular}


In the case of eigenvector centrality, the results show an identical situation as for the closeness centrality, i.e. H4b and $\mathrm{H} 4 \mathrm{~d}$ were supported and $\mathrm{H} 4 \mathrm{a}$ and $\mathrm{H} 4 \mathrm{c}$ were not supported. So, students who were connected to many other students that were themselves wellconnected had better grades for the evaluation grades for volume and for the final grades.

Lastly, of the hypotheses related with the average tie strength, only the grade for quality does not present a significant correlation with the measure and, as such, H5a was not supported. On the other hand, H5b, H5c and H5d were validated for this SNA measure, which means that students with strong ties have a better performance for the volume and diversity of work (and consequently for the final grade), than those with low ties. The coefficient of determination related with $\mathrm{H} 5 \mathrm{~b}$ represents the highest value obtained in this study. Therefore, the average tie strength helps to explain almost $61 \%$ of the variance on grades obtained by students for the volume of work.

\section{Conclusion and future work}

This paper presented shortly for the first time the concept and a case study of SNEE. This new learning methodology is in a development process but by this first experience and positive feedback given by students, it is believed that the right path to develop a good alternative approach for the students' learning process is being followed.

The results of this study suggest that interactions between students in SNEE are an important factor for the students' performance. A student had higher grades for volume of work and also higher final grades if he/she performed interactions with different other students, connected many pairs of other students, was very close to all other students, was connected to many other students that are themselves well-connected, and had strong ties (repeated interactions). Regarding the grade for quality, a student was most likely to had a high grade if he/she performed more tasks for different other students and was more frequently between the interaction paths of other students. Finally, a student who had high average tie strength, had a higher grade for diversity of work than those with a low average tie strength. Thus, the theory of "strength of strong ties", which was described in a previous section, can be validated in this study.

The contribution of this work to theoretical knowledge is mainly focused on a new type of learning methodology that can have a great impact on the students' learning process, fostering the development of new types of skills and contributing for the methodology of project-led education. Additionally, it might be said that the results contribute to a behavioural theory of learning performance. The results could be used also for designing of course structure and methodology improvement, in order to reinforce the correlations analysed.

The importance of applying the SNA for the evaluation of students' performance (in SNEE) is in making the student's performance evaluation based on student interactions (behaviour) analysis, in possibility of automation, or partial automation, of students' performance giving higher objectivity and productivity of the teachers, as well as better controlling by the students of their own performance and undertaking corresponding measures. Another important aspect of automatization of students' performance evaluation, as well as of the possibility for controlling the whole learning process directly and in realtime objectively, is its contribution to the capacity of education courses, and system, scalability. 
However, this study has still some limitations. It was not possible to perform a regression analysis to identify which of the independent variables (SNA measures) impacts the dependent variable (students' final grades), as the sample size used did not present enough explanatory power. Some students did not meet the rule of anonymity, i.e. analysing the interactions occurred it was clear that some resources' behaviour was to perform tasks for project coordinators they already knew well (that they are accustomed to work with and with whom they formed groups in previous projects).

Since this new learning methodology is in a development process, there is still a plenty of room for improvement. Further research is required to increase the sample size of the study to perform a regression analysis to understand which SNA measure can be used as predictors for the students' final grades, and consequently, for the students' evaluation process. Other improvements are also planned with the introduction of more rules for the projects: (1) project coordinators must be randomly selected, and not selected by their own initiative (to give equal opportunities to all students); (2) a resource cannot do the same task to multiple coordinators (to promote a more agile process); (3) individual resources can collaborate with each other (to foster the collaboration between small groups of students, e.g. collaboration for a maximum of 2-3 resources). It is very important to consider the aspect of collaboration between individual resources (last point), in order to increase the complexity of connections in the network, making the study even more interesting and taking another step towards the development of the SNEE methodology.

The authors would call for attention that the methodology was applied for the simulation and learning on the scenarios that corresponds to the common market scenario and philosophy, characterized by the competition among independent clients and service providers, while the SNEE application for a different concept that represents a collaborative "market", where the actors can communicate and share extensively relevant information and knowledge, i.e. not based on competition but on collaboration, will represent future work also.

Concerning the transferability of the findings it should be underlined that the results are transferable to virtually any engineering traditional subject, or course, as these subjects, or courses are in great part similar in the curricula structure and the education approach, while the subjects and courses in human sciences the transferability might be questioned due to more "non-mechanical" phenomena of application domains, and for these areas application of SNEE and its analysis would be also very interesting.

However, the most important parameter for the transferability of the findings in particular, is that the students and teachers form a network, but not any kind of network (because in the traditional methodology, e.g. "direct-instruction" and "teacher-centred education", the students and teachers also form a kind of network), but the network that exhibits features of a social network. In other words, the education process must be designed in a way that students, teachers, communication, learning process and behaviour, form the network that exhibits social network, or, using another term as a synonym, a "scale-free network" - which was the case in the experiment described and analysed in this paper.

Concerning the concrete action on transferability of the SNEE methodology and the related findings, at the moment of conclusion of this paper it is already decided to extend the application of the SNEE methodology and the related findings to two new subjects at the same engineering course (Industrial Engineering and Management Integrated Master Course at the University of Minho in Portugal), which proves the transferability of the methodology and the related findings, along with implementation of some other issues referred above as the future work. 
Finally, this work could be considered as a significant contribution to the implementation of Education 3.0 paradigm.

Acknowledgments The authors wish to acknowledge the support of the Fundação para a Ciência e Tecnologia (FCT), Portugal, through the Grants "Projeto Estratégico-UI 252-2011-2012" reference PEst-OE/EME/UI0252/2011, "Ph.D. Scholarship Grant" reference SFRH/BD/85672/2012, and the support of Parallel Planes Lda.

\section{References}

Abbasi, A., Altmann, J., \& Hossain, L. (2011). Identifying the effects of co-authorship networks on the performance of scholars: A correlation and regression analysis of performance measures and social network analysis measures. Journal of Informetrics, 5(4), 594-607.

Abbasi, A., Hossain, L., \& Leydesdorff, L. (2012). Betweenness centrality as a driver of preferential attachment in the evolution of research collaboration networks. Journal of Informetrics, 6(3), 403-412.

Ai, J., Zhao, H., Carley, K., Su, Z., \& Li, H. (2013). Neighbor vector centrality of complex networks based on neighbors degree distribution. The European Physical Journal B, 86(4), 1-7.

Bales, R. (1950). Interaction process analysis: A method for the study of small groups. Cambridge: AddisonWesley.

Barabási, A. (2002). Linked: The new science of networks. New York: Perseus Books.

Bonacich, P. (2007). Some unique properties of eigenvector centrality. Social Networks, 29(4), 555-564.

Borgatti, S. (1995). Centrality and AIDS. Connections, 18(1), 112-114.

Borgatti, S. (2006). Identifying sets of key players in a social network. Computational and Mathematical Organization Theory, 12(1), 21-34.

Borgatti, S., Everett, M., \& Freeman, L. (2002). UCINET for windows: Software for social network analysis (version 6). Harvard: Analytic Technologies.

Borgatti, S., \& Halgin, D. (2011). On network theory. Organization Science, 22(5), 1168-1181.

Borgatti, S., \& Li, X. (2009). On social network analysis in a supply chain context. Journal of Supply Chain Management, 45(2), 5-22.

Cimenler, O., Reeves, K., \& Skvoretz, J. (2014). A regression analysis of researchers' social network metrics on their citation performance in a college of engineering. Journal of Informetrics, 8(3), $667-682$.

Cohen, J. (1988). Statistical power analysis for the behavioral sciences. Hillsdale: Lawrence Erlbaum Associates.

Daly, A., Moolenaar, N., Bolivar, J., \& Burke, P. (2010). Relationships in reform: The role of teachers' social networks. Journal of Educational Administration, 48(3), 359-391.

Dewick, P., \& Miozzo, M. (2004). Networks and innovation: Sustainable technologies in Scottish social housing. $R \& D$ Management, 34(3), 323-333.

Dowdy, S., Wearden, S., \& Chilko, D. (2011). Statistics for research. New Jersey: Wiley.

Fernandes, S., Flores, M., \& Lima, R. (2007). Project-led education in Engineering: Monitoring and assessing the learning process. In Joining forces in engineering education towards excellence-Proceedings of the SEFI and IGIP joint annual conference 2007. Miskolc, Hungary.

Fernandes, S., Mesquita, D., Flores, M., \& Lima, R. (2014). Engaging students in learning: Findings from a study of project-led education. European Journal of Engineering Education, 39(1), 55-67.

Fidalgo, P. (2012). Learning networks and moodle use in online courses: a social network analysis study. Doctoral thesis, New University of Lisbon, Portugal.

Fitzpatrick, B., \& Lueck, J. (2010). The case against data lock-in. Queue, 8(10), 20.

Freeman, L. (1979). Centrality in social networks conceptual clarification. Social Networks, 1(3), 215-239.

Freeman, L. (2004). The development of social network analysis: A study in the sociology of science. Vancouver: Empirical Press.

Giger, E., Pinzger, M., \& Gall, H. (2012). Can we predict types of code changes? An empirical analysis. In Proceedings of the 9th IEEE Working conference on mining software repositories (MSR). Zurich, Switzerland.

Granovetter, M. (1973). The strength of weak ties. American Journal of Sociology, 78(6), 1360-1380.

Hanneman, R., \& Riddle, M. (2005). Introduction to social network methods. California: Riverside.

Hansen, M. (1999). The search-transfer problem: The role of weak ties in sharing knowledge across organization subunits. Administrative Science Quarterly, 44(1), 82-111. 
Hassan, I., Talib, N., Riaz, A., \& Iqbal, M. (2014). Influence of national and engineering culture on team role selection. International Journal of Technology and Design Education, 24(1), 91-105.

Hauke, J., \& Kossowski, T. (2011). Comparison of values of Pearson's and Spearman's correlation coefficients on the same sets of data. Quaestiones Geographicae, 30(2), 87-93.

Hawe, P., Webster, C., \& Shiell, A. (2004). A glossary of terms for navigating the field of social network analysis. Journal of Epidemiology and Community Health, 58(12), 971-975.

Helle, L., Tynjälä, P., \& Olkinuora, E. (2006). Project-based learning in post-secondary education-Theory, practice and rubber sling shots. Higher Education, 51(2), 287-314.

Hong, J., Hwang, M., Wong, W., Lin, H., \& Yau, C. (2012). Gender differences in social cognitive learning at a technological project design. International Journal of Technology and Design Education, 22(4), $451-472$.

Jippes, E., Achterkamp, M., Brand, P., Kiewiet, D., Pols, J., \& van Engelen, J. (2010). Disseminating educational innovations in health care practice: Training versus social networks. Social Science and Medicine, 70(10), 1509-1517.

Keats, D., \& Schmidt, J. P. (2007). The genesis and emergence of Education 3.0 in higher education and its potential for Africa. First Monday, 12(3). doi:10.5210/fm.v12i3.1625.

Krackhardt, D. (1992). The strength of strong ties: The importance of philos in organizations. In N. Nohria, \& R. G. Eccles (Eds.), Networks and organizations: Structure, form, and action (pp. 216-239). Boston: Harvard Business School Press.

Laat, M., Lally, V., Lipponen, L., \& Simons, R. (2007). Investigating patterns of interaction in networked learning and computer-supported collaborative learning: A role for Social Network Analysis. International Journal of Computer-Supported Collaborative Learning, 2(1), 87-103.

Lengel, J. G. (2013). Education 3.0: Seven steps to better schools. New York: Teachers College Press.

Levin, D., \& Cross, R. (2004). The strength of weak ties you can trust: The mediating role of trust in effective knowledge transfer. Management Science, 50(11), 1477-1490.

Liccardi, I., Ounnas, A., Pau, R., Massey, E., Kinnunen, P., Lewthwaite, S., et al. (2007). The role of social networks in students' learning experiences. ACM SIGCSE Bulletin, 39(4), 224-237.

Lima, R., Carvalho, D., Assunção Flores, M., \& Van Hattum-Janssen, N. (2007). A case study on project led education in engineering: Students' and teachers' perceptions. European Journal of Engineering Education, 32(3), 337-347.

Lomi, A., Snijders, T., Steglich, C., \& Torló, V. (2011). Why are some more peer than others? Evidence from a longitudinal study of social networks and individual academic performance. Social Science Research, 40(6), 1506-1520.

Martınez, A., Dimitriadis, Y., Rubia, B., Gómez, E., \& De La Fuente, P. (2003). Combining qualitative evaluation and social network analysis for the study of classroom social interactions. Computers and Education, 41(4), 353-368.

Obreiter, P., \& Gräf, G. (2002). Towards scalability in tuple spaces. In Proceedings of the 2002 ACM symposium on applied computing. Madrid, Spain.

Opsahl, T., Agneessens, F., \& Skvoretz, J. (2010). Node centrality in weighted networks: Generalizing degree and shortest paths. Social Networks, 32(3), 245-251.

Pallant, J. (2010). SPSS survival manual: A step by step guide to data analysis using SPSS. Philadelphia: McGraw-Hill International.

Palonen, T., \& Hakkarainen, K. (2000). Patterns of interaction in computer supported learning: A social network analysis. In Proceedings of the 4th international conference of the learning sciences. Ann Arbor, Michigan, USA.

Powell, P. (2004). Assessment of team-based projects in project-led education. European Journal of Engineering Education, 29(2), 221-230.

Powell, P., \& Weenk, W. (2003). Project-led engineering education. Utrecht: Lemma.

Putnik, G., Costa, E., Alves, C., Manupati, V., \& Castro, H. (2013). Social network analysis for social network-based projects in project-led education: A case study from an engineering course. In Proceedings of the 2nd international conference on virtual and networked organizations emergent technologies and tools (ViNOrg). Póvoa de Varzim, Portugal.

Rienties, B., \& Kinchin, I. (2014). Understanding (in) formal learning in an academic development programme: A social network perspective. Teaching and Teacher Education, 39, 123-135.

Russo, T., \& Koesten, J. (2005). Prestige, centrality, and learning: A social network analysis of an online class. Communication Education, 54(3), 254-261.

Tseng, K., Chang, C., Lou, S., \& Chen, W. (2013). Attitudes towards science, technology, engineering and mathematics (STEM) in a project-based learning (PjBL) environment. International Journal of Technology and Design Education, 23(1), 87-102. 
Van den Bossche, P., \& Segers, M. (2013). Transfer of training: Adding insight through social network analysis. Educational Research Review, 8, 37-47.

van Hattum-Janssen, N., \& Vasconcelos, R. (2008). The tutor in project-led education: Evaluation of tutor performance. In Proceedings of the 36th annual SEFI conference. Aalborg, Denmark.

Vercellone-Smith, P., Jablokow, K., \& Friedel, C. (2012). Characterizing communication networks in a web based classroom: Cognitive styles and linguistic behavior of self-organizing groups in online discussions. Computers and Education, 59(2), 222-235.

Vrabič, R., Husejnagić, D., \& Butala, P. (2012). Discovering autonomous structures within complex networks of work systems. CIRP Annals-Manufacturing Technology, 61(1), 423-426.

Wasserman, S. (1994). Social network analysis: Methods and applications. Cambridge: Cambridge University Press.

Wellman, B., \& Berkowitz, S. (1988). Social structures: A network approach. Cambridge: Cambridge University Press.

Wu, T. (2014). Using smart mobile devices in social-network-based health education practice: A learning behavior analysis. Nurse Education Today, 34(6), 958-963. 